Volume 2

Issue 4 -- Integrative Medicine

Article 39

$11-20-2015$

\title{
Contemporary Usage of Intra-Arterial Catheter-Directed Thrombolytic (CDT) Power Pulse Spray With Rheolytic Thrombectomy in Failed CDT Alone for Acute Limb Ischemia
}

Hani Hashim

M. Fuad Jan

Maharaj Singh

Suhail Allaqaband

Tanvir Bajwa

Anjan Gupta

Follow this and additional works at: https://aah.org/jpcrr

Part of the Cardiology Commons, and the Cardiovascular Diseases Commons

\section{Recommended Citation}

Hashim H, Jan M, Singh M, Allaqaband S, Bajwa T, Gupta A. Contemporary Usage of Intra-Arterial Catheter-Directed Thrombolytic (CDT) Power Pulse Spray With Rheolytic Thrombectomy in Failed CDT Alone for Acute Limb Ischemia. J Patient Cent Res Rev 2015;2:217. http://dx.doi.org/10.17294/ 2330-0698.1249

Published quarterly by Midwest-based health system Advocate Aurora Health and indexed in PubMed Central, the Journal of Patient-Centered Research and Reviews (JPCRR) is an open access, peer-reviewed medical journal focused on disseminating scholarly works devoted to improving patient-centered care practices, health outcomes, and the patient experience. 
Conclusion: These data demonstrate that contrary to the popular belief, significant systolic and diastolic pressure gradients distal to coronary stenosis exist with a reasonable but lower predictive power towards FFR $\leq 0.80$.

\section{Contemporary Usage of Intra-Arterial Catheter- Directed Thrombolytic (CDT) Power Pulse Spray With Rheolytic Thrombectomy in Failed CDT Alone for Acute Limb Ischemia}

Hani Hashim, M. Fuad Jan, Maharaj Singh, Suhail Allaqaband, Tanvir Bajwa, Anjan Gupta

Aurora Cardiovascular Services, Aurora Health Care; Aurora Research Institute, Aurora Health Care

Background: Acute lower limb ischemia (ALI) caused by arterial embolism, thrombosis of native vessels, and/ or grafts is a serious condition associated with substantial morbidity and mortality. Peripheral arterial thrombolysis utilizing catheter-directed thrombolytic (CDT) has become established as a useful option in the management of ALI. However, use and outcome of adjunctive power pulse spray with rheolytic thrombectomy (PPSRT) following unsuccessful CDT is underreported in the literature.

Purpose: To evaluate outcome of contemporary use of intraarterial CDT PPSRT as an adjunct to unsuccessful standard CDT for ALI.

Methods: We reviewed 78 consecutive patients (mean age $69 \pm$ 14.2 years, $48.8 \%$ female) who presented to Aurora St. Luke's Medical Center with less than 14 days of ALI from January 2004 to October 2014. All patients had percutaneous transluminal angioplasty procedures as a standard revascularization option for ALI. Data were collected from electronic medical records, and billing codes. Continuous variables were expressed as mean \pm standard deviation and range, and categorical variables as frequency count and percentage. Differences between the groups were analyzed with t-tests or analysis of variance and chi-square or Fisher's test.

Results: 48 patients (Group 1) underwent CDT alone with successful technical and clinical results, while 30 patients (Group 2) who had unsuccessful CDT results underwent adjunctive CDT with PPSRT. There was no statistical significance among both groups in regard to their baseline characteristics. In Group 1 and Group 2, respectively, limb salvage was $87.5 \%$ and $86.6 \%(\mathrm{P}=\mathrm{ns})$, amputation at 30 days $13 \%$ and $16 \%(\mathrm{P}=\mathrm{ns})$, embolectomy $16.67 \%$ and $20 \%(\mathrm{P}=\mathrm{ns})$, emergent bypass graft $8.3 \%$ and $13.33 \%(\mathrm{P}=\mathrm{ns})$, distal embolization $14.89 \%$ and $17.24 \%(\mathrm{P}=\mathrm{ns}), 30$-day compartmental syndrome $12.5 \%$ and $13.79 \%(\mathrm{P}=\mathrm{ns})$, death at 30 days $8.8 \%$ and $13.33 \%(\mathrm{P}=\mathrm{ns})$, and bleeding requiring blood transfusion $16 \%$ and $14 \%(\mathrm{P}=\mathrm{ns})$. Hemorrhagic stroke occurred in one patient of Group 1. Complete and partial analysis achieved in (Group 2) $73.4 \%$, length of hospitalization was $10.6 \pm 6.25$ days $(\mathrm{P}=\mathrm{ns})$.

Conclusion: Adding intra-arterial CDT power pulse spray with rheolytic thrombectomy to unsuccessful standard CDT as an adjunctive procedure is a powerful revascularization tool for lower extremity acute limb ischemia that achieves success in the vast majority of patients, is not associated with higher complications when compared to successful CDT alone, and obviates the need for emergent surgical revascularization.

\section{Additional Presentations}

The following citations reflect additional 2015 Aurora Scientific Day presentations, some of which have been published as abstracts or articles in scientific journals.

First Place Poster (tie): Ali Z, Greer DM, Shearer R, Alemu A, Jahangir A. Androgen suppression effects on heart failure and in patients with prostate cancer. $J$ Am Coll Cardiol. 2015;65(10S):A887.

Second Place Poster: Muluneh A, Nfor T, Bajwa T, Biru NY, Parmar HS, Greer DM, Belete HM. Evaluating MACE associated with temporary discontinuation of antiplatelets for acute GI bleeding in patients with coronary stents. Poster presented at Aurora Scientific Day, Milwaukee, WI, May 20, 2015.

Rieselbach Distinguished Paper \#2: Forgie MM, Greer DM, Kram JJF, Bernhard KA, Salvo NP, Siddiqui DS. A randomized control trial of Foley catheter placement for induction of labor: stylette versus no stylette. Orally presented at Aurora Scientific Day, Milwaukee, WI, May $20,2015$.

Rieselbach Distinguished Paper \#3: Yousaf H, Ahmad MN, Ammar KA, Yusuf SH, Ellis MK. Operating test characteristics of respiratory exchange ratio as a noninvasive measure of anaerobic threshold. Circulation. 2013;128:A13761.

Rieselbach Distinguished Paper \#4: Ali Z, Greer DM, Shearer R, Gardezi AS, Chandel A, Jahangir A. Effects of testosterone supplement therapy on cardiovascular outcomes in men with low testosterone. $\mathrm{J} \mathrm{Am} \mathrm{Coll} \mathrm{Cardiol.}$ 2015;65(10S):A1346.

Shi Y, Cho C, Garlie L, Perez R, Shearer R, Sulemanjee $\mathrm{N}$, Zwicke $\mathrm{D}$, Hastings $\mathrm{T}$, Cheema $\mathrm{O}$, Thohan $\mathrm{V}$. Echocardiographic markers of implantable cardioverterdefibrillator therapy. J Am Coll Cardiol. 2015;65(10S):A913.

Honoris L, DeFranco A, Port S, Cho C, Li D, Nasir K, Kronmal R, Barr RG, Budoff M. Correlation of coronary artery calcium scoring on ungated computed tomography compared to gated cardiac computed tomography scans from the multi-ethnic study of atherosclerosis. $J$ Am Coll Cardiol. 2015;65(10S):A1063. 